\title{
One-pot bioethanol production from cellulose by co-culture of Acremonium cellulolyticus and Saccharomyces cerevisiae
}

\author{
Enoch Y Park ${ }^{1,2^{*}}$, Kazuya Naruse ${ }^{2}$ and Tatsuya Kato ${ }^{2}$
}

\begin{abstract}
Background: While the ethanol production from biomass by consolidated bioprocess (CBP) is considered to be the most ideal process, simultaneous saccharification and fermentation (SSF) is the most appropriate strategy in practice. In this study, one-pot bioethanol production, including cellulase production, saccharification of cellulose, and ethanol production, was investigated for the conversion of biomass to biofuel by co-culture of two different microorganisms such as a hyper cellulase producer, Acremonium cellulolyticus C-1 and an ethanol producer Saccharomyces cerevisiae. Furthermore, the operational conditions of the one-pot process were evaluated for maximizing ethanol concentration from cellulose in a single reactor.

Results: Ethanol production from cellulose was carried out in one-pot bioethanol production process.

A. cellulolyticus C-1 and S. cerevisiae were co-cultured in a single reactor. Cellulase producing-medium supplemented with $2.5 \mathrm{~g} / \mathrm{l}$ of yeast extract was used for productions of both cellulase and ethanol. Cellulase production was achieved by $A$. cellulolyticus C-1 using Solka-Floc (SF) as a cellulase-inducing substrate. Subsequently, ethanol was produced with addition of both $10 \%(\mathrm{~V} / \mathrm{V})$ of S. cerevisiae inoculum and SF at the culture time of $60 \mathrm{~h}$. Dissolved oxygen levels were adjusted at higher than $20 \%$ during cellulase producing phase and at lower than $10 \%$ during ethanol producing phase. Cellulase activity remained 8-12 FPU/ml throughout the one-pot process. When 50-300 g SF/I was used in $500 \mathrm{ml}$ Erlenmeyer flask scale, the ethanol concentration and yield based on initial SF were as 8.7-46.3 g/l and 0.15-0.18 (g ethanol/g SF), respectively. In 3-I fermentor with 50-300 g SF/l, the ethanol concentration and yield were $9.5-35.1 \mathrm{~g} / \mathrm{l}$ with their yields of $0.12-0.19(\mathrm{~g} / \mathrm{g})$ respectively, demonstrating that the one-pot bioethanol production is a reproducible process in a scale-up bioconversion of cellulose to ethanol.

Conclusion: A. cellulolyticus cells produce cellulase using SF. Subsequently, the produced cellulase saccharifies the $\mathrm{SF}$, and then liberated reducing sugars are converted to ethanol by S. cerevisiae. These reactions were carried out in the one-pot process with two different microorganisms in a single reactor, which does require neither an addition of extraneous cellulase nor any pretreatment of cellulose. Collectively, the one-pot bioethanol production process with two different microorganisms could be an alternative strategy for a practical bioethanol production using biomass.
\end{abstract}

Keywords: Bioethanol, Cellulase, Biomass, Acremonium cellulolyticus C-1, Saccharomyces cerevisiae, Biorefinery

\footnotetext{
* Correspondence: acypark@ipc.shizuoka.ac.jp

${ }^{1}$ Laboratory of Biotechnology, Integrated Bioscience Section, Graduate

School of Science and Technology, Shizuoka University, 836 Ohya, Suruga-ku,

Shizuoka 422-8017, Japan

${ }^{2}$ Laboratory of Biotechnology, Faculty of Agriculture, Department of Applied

Biological Chemistry, Shizuoka University, 836 Ohya, Suruga-ku, Shizuoka

422-8017, Japan
}

\section{Biomed Central}

(c) 2012 Park et al.; licensee BioMed Central Ltd. This is an Open Access article distributed under the terms of the Creative Commons Attribution License (http://creativecommons.org/licenses/by/2.0), which permits unrestricted use, distribution, and reproduction in any medium, provided the original work is properly cited. 


\section{Background}

A co-culture as a mimic of natural environment has been used for biodegradation of aromatic compounds $[1,2]$ or for biological reduction of sulfate [3]. In addition, ethanol production from a mixture of glucose and xylose was applied using co-cultures of Pichia stipites with Zymomonas mobilis [4] or Saccharomyces cerevisiae [5]. Thus the co-culture is a potential bioprocess if there are no cross-interactions among microorganisms, and each microorganism metabolizing its substrate is unaffected by the presence of other microorganism.

To prepare lignocellulose for ethanol production, the substrate is normally either hydrolysed completely to the reducing sugars using mineral acids or solubilized with a milder pretreatment, leaving the residual cellulose to be saccharified enzymatically. For a conversion of this cellulose to ethanol, either diluted-acid hydrolysate [6] or cellulase-saccharified hydrolysate [7] was used for the co-culture using yeast with Escherichia coli or Z. mobilis, respectively. When acid-hydrolysate is used, detoxification of the inhibitory components is required to increase the yield. In addition, when glucose and xylose are converted by co-culture using different microorganisms to ethanol production, the saccharification process is still essentially required. Alternatively a one-step process, a combination of cellulase production, cellulose hydrolysis, and fermentation, was applied in the co-culture of Clostridium thermocellum and Z. mobilis in $10 \mathrm{ml}$ scale [8]. From this co-culture, $2.7 \mathrm{mg} / \mathrm{ml}$ of ethanol was produced from $10 \mathrm{mg} / \mathrm{ml}$ of cellulose. However, C. thermocellum was significantly inhibited at the low levels of ethanol, and leaving the undegraded cellulobiose in the co-culture inhibited the cell-associated cellobiase, which prevented the efficient conversion of cellulose to ethanol [8].

Recently, many researches have focused on the consolidated bioprocessing (CBP) for the simplification of the conversion process of cellulose to bioethanol $[9,10]$. The CBP was categorized into CBPs I and II. Category I CBP is an engineering method of a cellulase producer to be ethanologenic, while category II CBP of an ethanologen to be cellulolytic. A prototype model of CBP I is Trichoderma reesei [11] or C. thermocellum [12], which is one of the widely studied microorganisms because of producing several kinds of cellulases and $\beta$-glucosidases. These microorganisms can produce ethanol from cellulose, followed by the fermentation of the resulting sugars to ethanol in anaerobic growth conditions [13]. However, its ethanol yield, productivity, and ethanol tolerance are low due to the low expression of the relevant genes involved in ethanol fermentation or to the low activity of the enzymes encoded by these genes. These bottlenecks have to be solved to improve the feasibility of the CBP I microorganism.
The CBP II strain requires functional production and secretion of the variety of exoglucanases and endoglucanases, assimilation and fermentation on lignocellulose as a sole carbon source. Target microorganisms are engineered E. coli or Z. mobilis in bacteria, and S. cerevisiae in yeasts. Cellulolytic enzymes have been functionally expressed in some of yeasts [9], but the yeast has not been satisfied in anaerobic growth on cellulose. Recently, cellulases, xylanases, and amylases were expressed on the cell surface of S. cerevisiae [14-16] and $2.1 \mathrm{~g} / \mathrm{l}$ of ethanol was produced from $10 \mathrm{~g} / \mathrm{l}$ of phosphate-swollen amorphous cellulose using endoglucanase, cellobiohydrolase, and $\beta$-glucosidase displaying yeast [17]. Unfortunately, the expression of $T$. reesei cellobiohydrolases or exoglucanase, which play the critical role in cellulose degradation, is still poor in $S$. cerevisiae, and still remains lots of problems to be solved before a practical contribution to a worldwide energy supply.

In this study, one-pot bioethanol production system consisting of cellulase production from cellulose, saccharification of cellulose using cellulase in situ, and ethanol production was investigated. For one-pot ethanol production, understanding the concept of potential microorganisms to produce cellulase from cellulose and ethanol from hydrolysate is indispensable. Filamentous fungus Acremonium cellulolyticus, isolated in 1987 [18], was used in this study. The A. cellulolyticus produced cellulase from crystal cellulose [19], pretreated waste milk pack [20], and untreated waste paper sludge (PS) [21]. The cellulase activities of A. cellulolyticus were comparable to those of $T$. reesei origins, which was enough to proceed the bioconversion of waste office paper to L(+)-lactate [22] and gluconic acid [23]. For example, $160 \mathrm{~g} / \mathrm{l}$ of cellulose contained in the waste PS was successfully converted to $40 \mathrm{~g} / \mathrm{l}$ of ethanol in SSF using this cellulase and thermotolerant S. cerevisiae [24]. However, this kind of process is composed of two different and separate processes, such as cellulase and ethanol productions. A new emerging challenge of the one-pot ethanol process is to produce ethanol from cellulose in a single reactor using the co-culture of A. cellulolyticus and $S$. cerevisiae. A. cellulolyticus cells produce cellulase from cellulose, and the produced cellulase in situ saccharifies cellulose. S. cerevisiae cells consume the liberated reducing sugars and produce ethanol. Therefore, the combination of these different microorganisms has potentials for cellulase and ethanol productions.

This study is the first challenge for a practical application of ethanol production from cellulose in a single bioreactor using $A$. cellulolyticus and $S$. cerevisiae cells. A. cellulolyticus and S. cerevisiae cells grow in different media and different oxygen consumption for each other. For successful one-pot process for ethanol production, medium composition, times for inoculum of each 
microorganism and substrate addition should be carefully considered. This study demonstrated the high yield of ethanol production from biomass by optimizing these critical variables in one-pot bioethanol production.

\section{Results}

S. cerevisiae inoculum time on co-culture of A. cellulolyticus and S. cerevisiae in a shake flask.

Using cellulase-producing medium, one-pot bioethanol production was carried out as shown in Figure 1. The $2.5 \mathrm{ml}$ of A. cellulolyticus preculture and various inoculums of $S$. cerevisiae were co-cultured in cellulase producing-medium with $\mathrm{SF}$ as a cellulase-inducing substrate. $\mathrm{DCW}$ of $A$. cellulolyticus $\left(\mathrm{DCW}_{\mathrm{A}}\right)$ were in the range of 11.2-14.3 g/l (Additional file 1: Figure S1 A), and cellulase activity was 8-11.5 FPU/ml (Additional file
2: Figure S2 B). Cellulase activity and A. cellulolyticus cell growth did not show any co-operative inhibitory effects by the co-culture of S. cerevisiae and A. cellulolyticus, but $S$. cerevisiae cells did not grow at all (Additional file 1: Figure $\mathrm{S} 1 \mathrm{C}$ ). This indicates that nutrients for $S$. cerevisiae growth were depleted because both A. cellulolyticus and S. cerevisiae cells consumed glucose liberated by saccharification of SF. In order to let S. cerevisiae cells grow after inoculation, residual glucose has to be present in culture. To decipher this optimal condition, co-culture was carried out with different $S$. cerevisiae inoculum time. When $S$. cerevisiae inoculum was added in the late exponential and stationary growth phases of A. cellulolyticus (Figure 2), cellulase activity was increased in the late exponential growth phase of A. cellulolyticus $(48-60 \mathrm{~h})$ and remained the highest

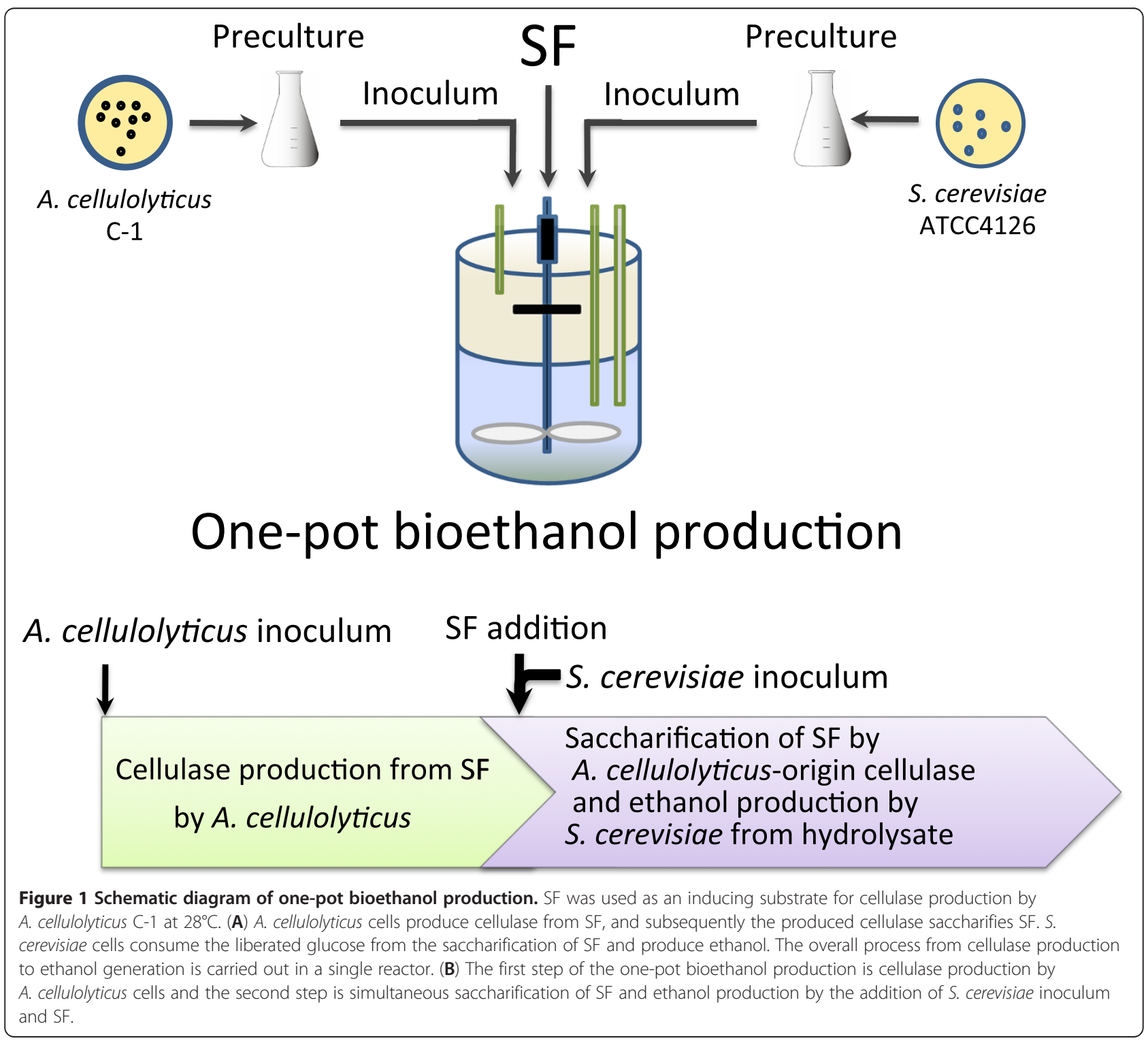



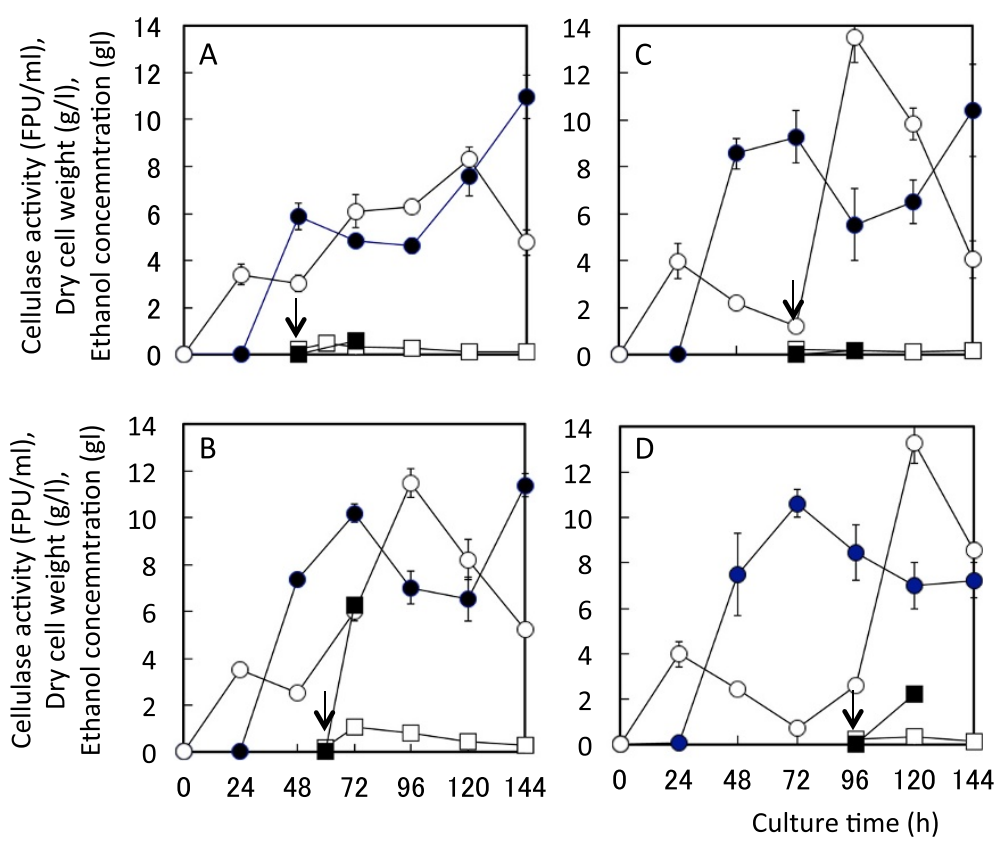

Figure 2 Effect of the $S$. cerevisiae inoculum time and SF addition time on cellulase activity, $\mathrm{DCW}_{\mathrm{A}}, \mathrm{DCW}_{\mathrm{S}}$, and ethanol concentration in co-culture of $\boldsymbol{A}$. cellulolyticus and $\boldsymbol{S}$. cerevisiae. Co-culture was carried out using cellulase producing-medium containing $2.5 \mathrm{~g} / \mathrm{l}$ of yeast extract in a shake flask with shaking at $220 \mathrm{rpm}$. Ethanol production was started by additions of $10 \%$ inoculum of $\mathrm{S}$. cerevisiae and $50 \mathrm{~g} / \mathrm{l}$ of

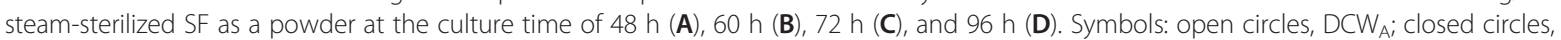
cellulase activity; open squares, DCWs; closed squares, ethanol concentration. Arrows indicate the addition times. Error bars denote standard deviation $(n=3)$.

activity in the stationary growth phase (72-96 h). Based on this finding, S. cerevisiae inoculum was added at four different culture times of 48,60, 72, and $96 \mathrm{~h}$. The cellulase activity was not affected by $S$. cerevisiae inoculum times of 48 and $60 \mathrm{~h}$ and maintained around $10 \mathrm{FPU} / \mathrm{ml}$ (Figure 2A and B). However, when the S. cerevisiae inoculum was added after the maximum cellulase activity, the cellulase activity decreased but $\mathrm{DCW}_{\mathrm{A}}$ rebounded (Figure 2C and D). As A. cellulolyticus cells depleted nutrients, $S$. cerevisiae cells could not grow, resulting in below $1 \mathrm{~g} / \mathrm{l} \mathrm{DCW}$ of $S$. cerevisiae $\left(\mathrm{DCW}_{\mathrm{s}}\right.$ ) (Figure $2 \mathrm{~A}-$ D). Ethanol concentration was $6.24 \mathrm{~g} / \mathrm{l}$ at the inoculum time of $60 \mathrm{~h}$ (Figure 2B), and those at other inoculum times were below $2 \mathrm{~g} / \mathrm{l}$. Thus, to maximize the ethanol production in the co-culture of two different microorganisms, $60 \mathrm{~h}$ of inoculation time was determined.

\section{Medium preparation for one-pot bioethanol production in a shake flask}

When both $A$. cellulolyticus and $S$. cerevisiae cells were co-cultured in a single reactor, $\mathrm{DCW}_{\mathrm{S}}$ was at low levels (Additional file 1: Figure S1). Although cellulase production was followed by $S$. cerevisiae inoculum, $\mathrm{DCW}_{\mathrm{S}}$ was still at low levels (Figure 2B). It means that it is difficult to get efficient production of ethanol in onepot because of slow growth of $S$. cerevisiae due to depletion of nutrients. To promote the growth of S. cerevisiae, $0-5 \mathrm{~g} / \mathrm{l}$ of yeast extract, $0-10 \mathrm{~g} / \mathrm{l}$ of polypeptone, and their combined nutrients were added to cellulase-producing medium, respectively (Additional file 2: Figure S2). A. cellulolyticus cell growth was similar (Additional file 2: Figure S2 A) but cellulase activity was maintained higher than that without its addition (Additional file 2: Figure S2 B), suggesting that yeast extract and polypeptone were not inhibitory to the cellulase production in this co-culture. Ethanol production was increased to $40 \%$ by addition of $5 \mathrm{~g} / \mathrm{l}$ of yeast extract compared to that without its addition (Additional file 2: Figure S2 C). Minimum requirement of yeast extract concentration for bioethanol production in $S$. cerevisiae was tested in the range of $0-7.5 \mathrm{~g} / \mathrm{l}$ addition (Additional file 3: Figure S3). A. cellulolyticus cell growth and cellulase production were not affected by yeast extract addition (Additional file 3: Figure S3 A and B). The growth of S. cerevisiae was improved by 2-3 fold compared to that without its addition (Additional file 3: Figure S3 C). Since significant effect on ethanol production was not observed (Additional file 3: Figure S3 D), $2.5 \mathrm{~g} / \mathrm{l}$ of yeast extract was added to cellulase-producing medium for stable growth of S. cerevisiae in the co-culture of two microorganisms. Thus, the minimal supplement of yeast extract 
significantly promoted the ethanol production as well as the growth of S. cerevisiae.

\section{Effect of temperature on cellulase production}

In an ethanol production using the co-culture process, maintaining the cellulase activity in a high temperature without deactivation of the enzymatic activities is integral. Temperature is a critical factor for the stability of cellulase produced by $A$. cellulolyticus. Cellulase production was carried out in a wide range of culture temperatures. The maximum $\mathrm{DCW}_{\mathrm{A}}$ at the cultures of 24 and $28^{\circ} \mathrm{C}$ were 9.4 and $10.1 \mathrm{~g} / \mathrm{l}$, respectively, but those at 32 and $36^{\circ} \mathrm{C}$ were below $8 \mathrm{~g} / \mathrm{l}$; at 40 and $44^{\circ} \mathrm{C}$ the A. cellulolyticus couldn't grow (Figure 3A). Specific growth rates of A. cellulolyticus at 28 and $32^{\circ} \mathrm{C}$ were 0.07 and $0.49 \mathrm{~h}^{-1}$, respectively. Cellulase activity at the culture of $32^{\circ} \mathrm{C}$ reached to $14 \mathrm{FPU} / \mathrm{ml}$, but that was $12.5 \mathrm{FPU} / \mathrm{ml}$ at $28^{\circ} \mathrm{C}$, $11 \mathrm{FPU} / \mathrm{ml}$ at $24^{\circ} \mathrm{C}, 6 \mathrm{FPU} / \mathrm{ml}$ at $36^{\circ} \mathrm{C}$, and $0 \mathrm{FPU} / \mathrm{ml}$ at 40 and $44^{\circ} \mathrm{C}$ (Figure 3B). Overall, the cellulase production rates at 28 and $32^{\circ} \mathrm{C}$ were 0.18 and $0.19 \mathrm{FPU} / \mathrm{ml} / \mathrm{h}$, respectively. There was no significant difference in cellulase activity between $28^{\circ} \mathrm{C}$ and $32^{\circ} \mathrm{C}$, but specific cellulase activity was more than $1 \mathrm{FPU} / \mathrm{mg}$ protein at $32^{\circ} \mathrm{C}$ (Figure 3C). These results indicate that the optimal temperature for cellulase production is $32^{\circ} \mathrm{C}$.

\section{Effect of agitation rate on the productions of cellulase} and ethanol in co-culture

Normally, the cellulase production by A. cellulolyticus cells was carried out in an aerobic condition whereas the ethanol production by $S$. cerevisiae cells in an anaerobic condition. To determine the logical conditions of oxygen supply, the effect of agitation rate on cellulase activity and ethanol production was investigated in a flask scale with different agitation rates (Figure 4). In the cellulase production phase the $\mathrm{DCW}_{\mathrm{A}}$ reached $10 \mathrm{~g} / \mathrm{l}$ at $220 \mathrm{rpm}$, but didn't show significant change at 80 and $130 \mathrm{rpm}$ (Figure 4A). On the other hand, the $\mathrm{DCW}_{\mathrm{S}}$ in the ethanol production phase was tending to decrease with increased agitation rate (Figure 4B). The ethanol concentration was high at low agitation rate, but the cellulase activity was high at high agitation rate (Figure 4C). These findings suggest that the decreasing dissolved oxygen level followed by addition of $S$. cerevisiae inoculum is preferred for ethanol production in the co-culture of A. cellulolyticus and S. cerevisiae.

\section{One-pot bioethanol production from SF in a shake flask}

According to the determined conditions, one-pot bioethanol production was carried out with different initial SF concentrations from 50 to $150 \mathrm{~g} / \mathrm{l}$ (Figure 5). $\mathrm{DCW}_{\mathrm{A}}$ at 50,100 , and $150 \mathrm{~g} \mathrm{SF} / 1$ were $7.9,8.0$, and $8.3 \mathrm{~g} / \mathrm{l} ; \mathrm{DCW}_{\mathrm{S}}$ were $12.3,13.0$, and $12.5 \mathrm{~g} / \mathrm{l}$. The cell growth of A. cellulolyticus and S. cerevisiae did not show significant change. Residual glucose concentration at 50 , 100 , and $150 \mathrm{~g} \mathrm{SF} / \mathrm{l}$ were $6.8,9.8$, and $11 \mathrm{~g} / \mathrm{l}$, respectively (Figure 5A). During this process the cellulase activity remained at 7.5-8.5 $\mathrm{FPU} / \mathrm{ml}$ without deactivation, but ethanol concentration was increased with increased SF concentration (Figure 5B). In addition, the $Y_{e / S F}$ for 50 , 100 , and $150 \mathrm{~g} \mathrm{SF} / \mathrm{l}$ remained constant at $0.18 \mathrm{~g} / \mathrm{g}$, not affected by the initial amount of SF.

To improve the ethanol concentration, initial SF was $150 \mathrm{~g} / \mathrm{l}$ at $60 \mathrm{~h}$ and another $150 \mathrm{~g} \mathrm{SF} / \mathrm{l}$ was added during ethanol fermentation at 72, 78, and $84 \mathrm{~h}$ (Figure $5 \mathrm{C}$ and D). The cellulase activity was 9-11.5 FPU/ml (Figure 5C), which was not affected by addition of SF during the ethanol production. Ethanol concentration was $26.7 \mathrm{~g} / \mathrm{l}$ from $150 \mathrm{~g} \mathrm{SF} / \mathrm{l}$, but it increased to $45-46.3 \mathrm{~g} / \mathrm{l}$ by addition of $150 \mathrm{~g} / \mathrm{l} \mathrm{SF}$ (Figure 5D). $Y_{e / S F} \mathrm{~s}$ for addition $150 \mathrm{~g} \mathrm{SF} / \mathrm{l}$ at 72, 78 , and $84 \mathrm{~h}$ were the same values of $0.15 \mathrm{~g} / \mathrm{g}$, respectively; overall ethanol production rate $\left(V_{\mathrm{e}}\right), 0.45-0.48 \mathrm{~g} / \mathrm{l} / \mathrm{h}$. This result indicates that cellulase activity remained enough to saccharify SF in the ethanol production phase and simultaneously $S$. cerevisiae cells were active in the ethanol fermentation phase.
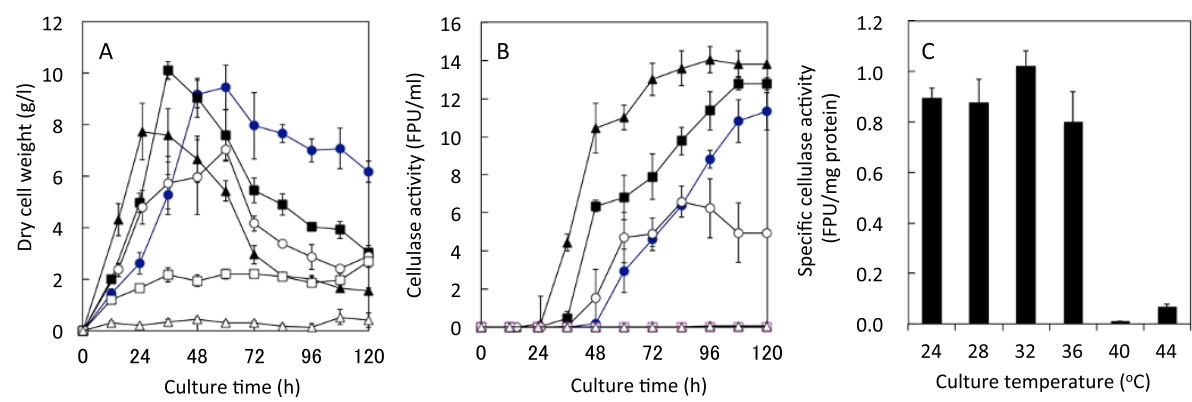

Figure 3 Effect of the temperature in the culture of A. cellulolyticus C-1 on cell growth (A), cellulase activity (B), and specific cellulase activity (C). Cellulase producing medium was used with SF as a sole inducing substrate for cellulase production at different culture temperatures $\left(24,28,32,36,40\right.$, and $\left.44^{\circ} \mathrm{C}\right)$. Symbols in $\mathbf{A}$ and $\mathbf{B}$ : closed circles, $24^{\circ} \mathrm{C}$; closed squares, $28^{\circ} \mathrm{C}$; closed triangles, $32^{\circ} \mathrm{C}$; open circles, $36^{\circ} \mathrm{C}$; open squares, $40^{\circ} \mathrm{C}$; open triangles, $44^{\circ} \mathrm{C}$. Error bars denote standard deviation $(n=3)$. As determined by ANOVA analysis, the cellulase activities affected by culture temperature in B are significant at $p<0.0001$. 

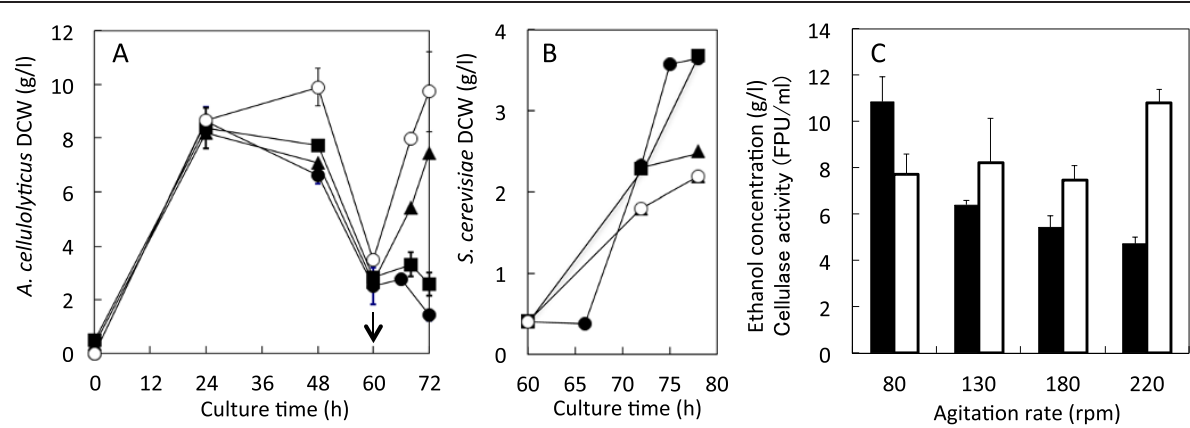

Figure 4 Effect of the agitation rate on $\mathrm{DCW}_{\mathrm{A}}(\mathrm{A}), \mathrm{DCW}_{\mathrm{S}}(\mathrm{B})$, and ethanol concentration and cellulase activity $(\mathrm{C})$ in co-culture of A. cellulolyticus and S. cerevisiae. Ethanol production was carried out as the same method of Fig. 3, except for agitation rates, 80-220 rpm. Symbols in $\mathbf{A}$ and $\mathbf{B}$ : closed circles, $80 \mathrm{rpm}$; closed squares, $130 \mathrm{rpm}$; closed triangles, $180 \mathrm{rpm}$; open circles, $220 \mathrm{rpm}$. Closed and open bars in $\mathbf{C}$ denote ethanol concentration and cellulase activity, respectively. Arrow indicates inoculum and SF-addition time. Error bars denote standard deviation $(n=3)$. As determined by ANOVA analysis, the ethanol concentrations and cellulase activities affected by agitation rate in $\mathbf{D}$ are significant at $p<0.001$ and $p<0.0001$, respectively.

\section{Improved one-pot bioethanol production from SF in} fermentor

Jar fermentor was used to validate the one-pot bioethanol production using two microorganisms with $50 \mathrm{~g} \mathrm{SF} / \mathrm{l}$. An agitation rate during cellulase production was kept at
$500 \mathrm{rpm}$ and at the culture time of $60 \mathrm{~h}$, and decreased to $200 \mathrm{rpm}$ during ethanol production phase, which resulted in the drop in dissolved oxygen level to $0 \%$ (Figure 6A). DCW $\mathrm{A}$ was the highest at $24 \mathrm{~h}$ culture, and then cellulase activity increased to $9 \mathrm{FPU} / \mathrm{ml}$ (Figure 6B).
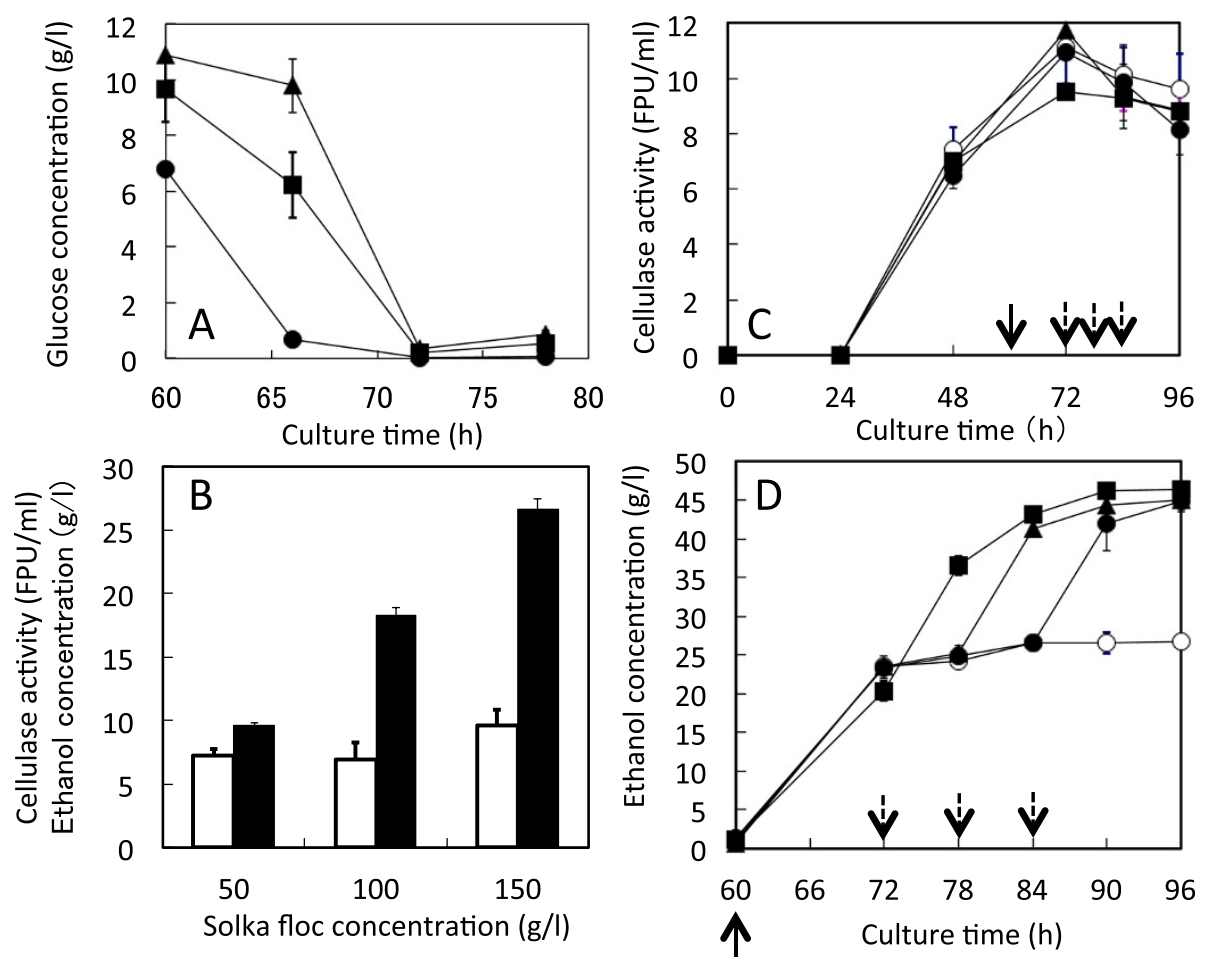

Figure 5 One-pot bioethanol productions in a shake flask. (A) and (B): Co-culture of A. cellulolyticus and S. cerevisiae was carried out with different SF concentration, 50, 100, and $150 \mathrm{~g} / \mathrm{l}$. (C) and (D): Co-culture of A. cellulolyticus and S. cerevisiae was carried out with $150 \mathrm{~g} \mathrm{SF/I}$ concentration at the culture time of $60 \mathrm{~h}$, and another $150 \mathrm{~g} \mathrm{SF/I} \mathrm{was} \mathrm{added} \mathrm{at} 72 \mathrm{~h}$. Similar co-cultures were done with $150 \mathrm{~g} \mathrm{SF/I} \mathrm{concentration}$ at the culture time of $60 \mathrm{~h}$, and another $150 \mathrm{~g} \mathrm{SF/l} \mathrm{was} \mathrm{added} \mathrm{at} 78 \mathrm{~h}$ or $84 \mathrm{~h}$. Symbols in A: closed circles, $50 \mathrm{~g} / \mathrm{l} \mathrm{SF}$; closed squares, $100 \mathrm{~g} / \mathrm{l} \mathrm{SF}$; closed triangles, $150 \mathrm{~g} / \mathrm{S}$ SF. Bars in B: open bars, cellulase activity; closed bars, ethanol concentration. Symbols in C and D: open circles, without addition; closed squares, addition time 72 h; closed triangles, addition time 78 h; closed circles, addition time 84 h. Arrows indicate SF-addition times. Error bars denote standard deviation $(n=3)$. As determined by ANOVA analysis, the ethanol productions by increased SF concentration in $\mathbf{B}$ and $\mathbf{D}$ are significant at $p<0.05$ and $p<0.005$. 
When SF and S. cerevisiae inoculum were added, residual glucose concentration was $8.2 \mathrm{~g} / \mathrm{l}$, and dropped to $0 \mathrm{~g} / \mathrm{l}$ after the culture of $66 \mathrm{~h}$ (Figure 6B). Ethanol concentration reached to $9.5 \mathrm{~g} / \mathrm{l}$ at culture time of $72 \mathrm{~h}$, and $Y_{e / S F}$ was $0.19 \mathrm{~g} / \mathrm{g}$.

SF concentration was added another $150 \mathrm{~g} / \mathrm{l}$ at the culture time of $66 \mathrm{~h}$ as the same cultural condition as Figure $6 \mathrm{~A}$ and $\mathrm{B}$. When the agitation rate was decreased to $200 \mathrm{rpm}$ at the culture time of $60 \mathrm{~h}$, the dissolved oxygen level was dropped to $0 \%$, but increased gradually as high as $20 \%$ at the culture time of $66 \mathrm{~h}$ (Figure 6C). Cellulase activity was $12 \mathrm{FPU} / \mathrm{ml}$ at maximum and remained $10 \mathrm{FPU} / \mathrm{ml}$ during the ethanol production phase (Figure 6D). The ethanol concentration was increased sharply reaching $35.1 \mathrm{~g} / \mathrm{l}$ (Figure 6D) at the culture time of $72 \mathrm{~h}$, and the $Y_{e / S F}$ and $V_{\mathrm{e}}$ values were $0.12 \mathrm{~g} / \mathrm{g}$ and $0.49 \mathrm{~g} / \mathrm{l} / \mathrm{h}$, respectively. Thus, one-pot bioethanol production from cellulose by two microorganisms is applicable to a jar fermentor scale production platform.

\section{Discussion}

While the CBP is considered as the most ideal process, $\mathrm{CBP}$ is not useful in practice due to low ethanol concentration and its low yield. Alternatively, a simultaneous saccharification and fermentation (SSF) is an appropriate method for bioethanol production, but, in SSF, cellulase production process is excluded. Previous study reported that the ethanol concentration and yield based on initial cellulose were $36.5 \mathrm{~g} / \mathrm{l}$ and 0.25 (g ethanol/g PS cellulose) from $150 \mathrm{~g} / \mathrm{l}$ of cellulose contained in PS, respectively with cellulase loading of $15 \mathrm{FPU} / \mathrm{g}$ PS cellulose [24]. In the SSF, the total reaction time was $80 \mathrm{~h}$, but when cellulase production process is included, it was at least $140 \mathrm{~h}$, meaning that the $V_{\mathrm{e}}$ was $0.26 \mathrm{~g} / \mathrm{l} / \mathrm{h}$.

In this one-pot bioethanol production process the productions of cellulase and ethanol were carried out by A. cellulolyticus and S. cerevisiae, respectively, in a single reactor. The total reaction time was dramatically reduced to $72 \mathrm{~h}$ including cellulase production, saccharification, and ethanol fermentation. During this process, the cellulase activity was not deactivated and remained constant (Figures 5B, 6B and D), enough to saccharify SF. The ethanol concentration was $25.6 \mathrm{~g} / \mathrm{l}$ from $150 \mathrm{~g}$ $\mathrm{SF} / \mathrm{l}$ with the $Y_{e / S F}$ of $0.17 \mathrm{~g} / \mathrm{g}$, which was $70 \%$ comparing to that of the SSF. However, the $V_{\mathrm{e}}$ was $0.36 \mathrm{~g} / \mathrm{l} / \mathrm{h}$, which is 1.4 fold to that of SFF. When $300 \mathrm{~g} / \mathrm{l} \mathrm{SF}$ was used in flask with cellulase loading of $25 \mathrm{FPU} / \mathrm{g}$ SF to increase ethanol concentration, the produced ethanol concentration, $Y_{e / S F}$ and $V_{\mathrm{e}}$ were $46.3 \mathrm{~g} / \mathrm{l}, 0.15 \mathrm{~g} / \mathrm{g}$, and $0.48 \mathrm{~g} / \mathrm{l} / \mathrm{h}$, respectively (Figure $5 \mathrm{D})$. However, in jar-fermentor, ethanol concentration, $Y_{e / S F}$ and $V_{\mathrm{e}}$ were $35.1 \mathrm{~g} / \mathrm{l}, 0.12 \mathrm{~g} / \mathrm{g}$, and $0.49 \mathrm{~g} / \mathrm{l} / \mathrm{h}$, respectively (Figure 6D).

The $V_{\mathrm{e}}$ was improved $1.4-1.9$-folds to that of SSF, indicating that the cellulase produced from $A$. cellulolyticus was highly stable and remained high activity without deactivation. The cellulase activity of firstly isolated A. cellulolyticus was only $5.0 \mathrm{FPU} / \mathrm{ml}$ using cellu lose powder [18]. However, this activity was still insufficient for the saccharification of cellulolytic biomass
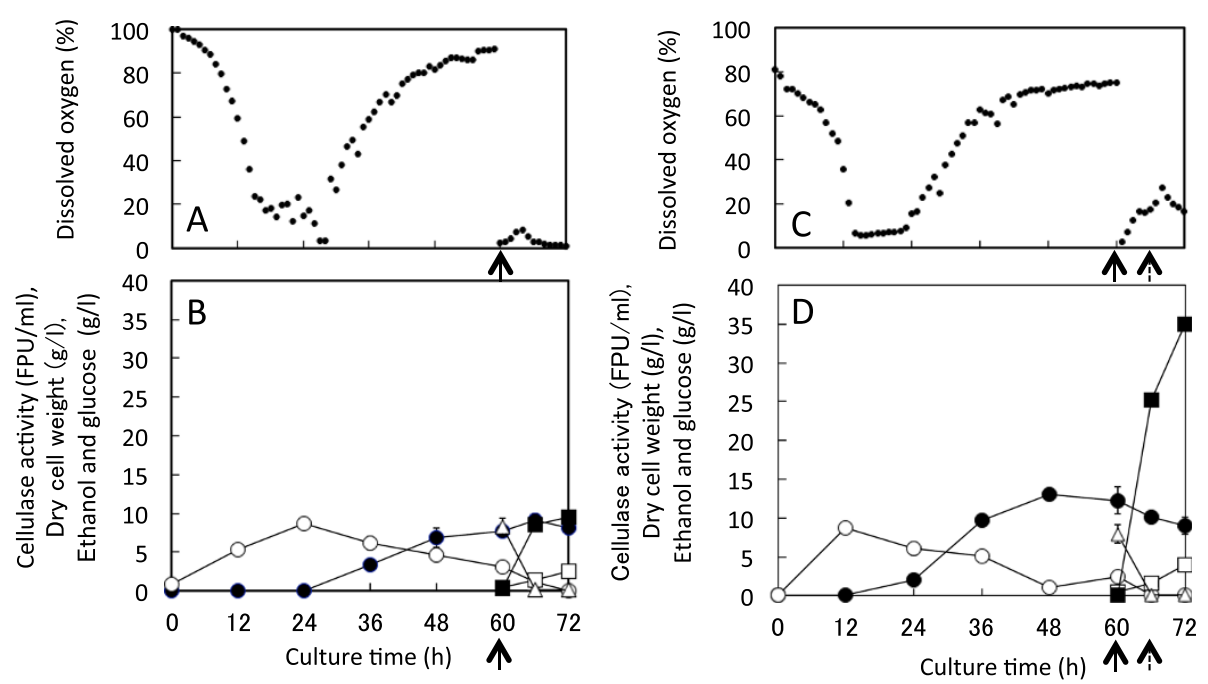

Figure 6 One-pot bioethanol productions in a jar fermentor. (A) and (B): Co-culture of A. cellulolyticus and S. cerevisiae was carried out with addition of $50 \mathrm{~g} \mathrm{SF} / \mathrm{l}$ at the culture time of $60 \mathrm{~h}$. (C) and (D): Co-culture of A. cellulolyticus and S. cerevisiae was carried out with addition of $150 \mathrm{~g}$ $\mathrm{SF} / \mathrm{l}$ at the culture times of 60 and $66 \mathrm{~h}$. Agitation rate was $500 \mathrm{rpm}$ during cellulase production, but dropped to $200 \mathrm{rpm}$ at the culture time of $60 \mathrm{~h}$ for ethanol production. Symbols in B and D: open circles, DCW ; closed circles, cellulase activity; open triangles, glucose concentration; open squares, DCW ; closed squares, ethanol concentration. Arrows indicate SF-addition times. Error bars denote standard deviation $(n=3)$. As determined by ANOVA analysis, the ethanol productions in $\mathbf{B}$ and $\mathbf{D}$ are both significant at $p<0.0001$. 
industrially. We improved the cell line and optimized its medium for the practical production of cellulase and obtained 15.5 FPU/ml in the flask culture, 17.42 FPU/ml in the $7-\mathrm{L}$ bioreactor, and $13.08 \mathrm{FPU} / \mathrm{ml}$ in the $50-\mathrm{L}$ bioreactor [19]. A. cellulolyticus produces a complex mixture of cellulases, mainly comprised of four $\beta$-glucosidases (EC 3.2.1.21) and twelve distinct endocellulases/carboxymethyl cellulases (CMCases, EC 3.2.1.4) [18,25]. Other polysaccharide hydrolyzing enzymes, such as xylanases, amylases and $\beta$-1,3-glucanases are also present [26]. The most important enzyme in this mixture for the current process is an endo-cellulose type III-A that can produce glucose from cellulose without any participation of $\beta$-glucosidase [26]. In contrast, it is well known that the Trichoderma enzymes do not effectively saccharify cellulose alone because of their low $\beta$-glucosidase activity. When $A$. cellulolyticus cellulase and Trichoderma enzymes, GC220 were compared for saccharification of waste paper, their glucose contents among the hydrolysates were 83 and 72\%, respectively [19]. Because the genus of Trichoderma generally produces relatively low $\beta$-glucosidase in its cellulolytic enzymes, those enzymes cannot convert cellulolytic biomass to glucose efficiently without addition of extraneous $\beta$-glucosidase. It is very important to have higher glucose contents in the hydrolysate since it is only glucose that $S$. cerevisiae can easily uptake.

Although this one-pot bioethanol production process significantly improve overall ethanol production rate, low $Y_{e / S F}$ is still remained as an issue to be resolved. In the ethanol production phase A. cellulolyticus and $S$. cerevisiae cells consume glucose both for productions of cellulase and ethanol, respectively, and for their cellular maintenances, which cause the $Y_{e / S F}$ decreased. It is better to keep in anaerobic condition in the ethanol production phase, but it was necessary to some extent agitation rate to avoid a precipitation of SF inside the reactor. To keep anaerobic condition, it may be effective to purge a nitrogen gas, but $A$. cellulolyticus cells cannot be alive. In this experiment, the dissolved oxygen level in the ethanol production phase increased to $20 \%$, which might decrease the carbon flux from glucose to ethanol. It is necessary to optimize the dissolved oxygen both for maximizing ethanol production and for maintaining A. cellulolyticus cells actively. So far, this one-pot bioethanol production is an alternative strategy as a mimic of CBP, because cellulase production, saccharification of carbohydrate, and ethanol fermentation occur in a single reactor.

\section{Conclusion}

This study establishes a method for practical one-pot bioethanol production from SF neither addition of extraneous cellulase nor pretreatment of cellulose. This one- pot bioethanol production includes cellulase production by $A$. cellulolyticus, saccharification of cellulose by cellulase in situ, and then ethanol production by $S$. cerevisiae from liberated reducing sugars in a single reactor. The potential of this process was also demonstrated in a stable and practical biorefinery using cellulosic biomass. Control of operational parameters, dissolved oxygen level, cellulose addition time, and $S$. cerevisiae inoculum time are still important for improving ethanol production in the co-culture with two different microorganisms. In particular, maintaining as higher than 20\% and lower than $10 \%$ dissolved oxygen levels at cellulase and ethanol production phases, respectively, could be crucial for maximizing the one-pot bioethanol production. Further studies are planned to allow the improved ethanol yield from different cellulosic biomass and to be scaled up.

\section{Methods}

\section{Raw materials}

Solka-Floc (SF; CAS \#9004-34-6; International Fiber Co., New York, USA) was used for cellulase and ethanol production. SF is a fine white powder comprised of approximately $70-80 \%$ crystalline cellulose and 20-30\% amorphous cellulose. Medium components and other chemicals were purchased from Wako Pure Chem. Co. Ltd. (Tokyo, Japan) and stored at a room temperature.

\section{Microorganisms}

A. cellulolyticus C-1 (Ferm P-18508), which is a hyper cellulase producer, and a mutant of wild type A. cellulolyticus Y-94, was provided by Tsukishima Kikai Co. Ltd. (Tokyo) [19]. S. cerevisiae ATCC 4126 (American Type Culture Collection, University Boulevard Manassas, VA, USA) was used for ethanol production in co-culture with A. cellulolyticus $\mathrm{C}-1$.

\section{Culture media}

The preculture medium for $A$. cellulolyticus is consisted (per liter) of $40 \mathrm{~g} \mathrm{SF}, 24 \mathrm{~g}$ of $\mathrm{KH}_{2} \mathrm{PO}_{4}, 1 \mathrm{ml}$ of Tween 80 (MP Biomed. Co. Ltd., OH, USA), $5 \mathrm{~g}$ of $\left(\mathrm{NH}_{4}\right)_{2} \mathrm{SO}_{4}$, $4.7 \mathrm{~g}$ of $\mathrm{K}_{2} \mathrm{C}_{4} \mathrm{H}_{4} \mathrm{O}_{6} \cdot 4 \mathrm{H}_{2} \mathrm{O}, 1.2 \mathrm{~g}$ of $\mathrm{MgSO}_{4} \cdot 7 \mathrm{H}_{2} \mathrm{O}, 10 \mathrm{mg}$ of $\mathrm{ZnSO}_{4} \cdot 7 \mathrm{H}_{2} \mathrm{O}, 9.28 \mathrm{mg}$ of $\mathrm{MnSO}_{4} \cdot 7 \mathrm{H}_{2} \mathrm{O}, 8.74 \mathrm{mg}$ of $\mathrm{CuSO}_{4} \cdot 7 \mathrm{H}_{2} \mathrm{O}$ and $2 \mathrm{~g}$ of urea $(\mathrm{pH} 4.0)$. The medium was sterilized at $121^{\circ} \mathrm{C}$ for $20 \mathrm{~min}$, with separately sterilized $\mathrm{ZnSO}_{4} \cdot 7 \mathrm{H}_{2} \mathrm{O}, \mathrm{MnSO}_{4} \cdot 7 \mathrm{H}_{2} \mathrm{O}$ and $\mathrm{CuSO}_{4} \cdot 7 \mathrm{H}_{2} \mathrm{O}$. Urea was sterilized by filtering through a $0.45 \mu \mathrm{m}$ filter membrane (Toyo Roshi Kaisha Co. Ltd., Tokyo, Japan).

The preculture medium for $S$. cerevisiae is consisted (per liter) of $50 \mathrm{~g}$ glucose, $50 \mathrm{~g} / \mathrm{l}$ YPD medium containing less than $0.04 \%$ of adenine (Sigma-Aldrich Co. Ltd., St. Louis, MO, USA). The YPD medium was composed of $20 \mathrm{~g} / \mathrm{l}$ of bacteriological peptone, $10 \mathrm{~g} / \mathrm{l}$ of yeast extract and $20 \mathrm{~g} / \mathrm{l}$ of glucose. 


\section{Co-culture of $A$. cellulolyticus and S. cerevisiae}

Seed cultivation of A. cellulolyticus was carried out using $5 \mathrm{ml}$ medium in a test tube at $28^{\circ} \mathrm{C}$ and 220 revolution per min (rpm) for $65 \mathrm{~h}$. Cellulase production was carried out in $500 \mathrm{ml}$ Erlenmeyer flask with $50 \mathrm{ml}$ medium at $28^{\circ} \mathrm{C}$ and $220 \mathrm{rpm}$ after addition of $A$. cellulolyticus inoculum with its volume fraction of $5 \%(\mathrm{v} / \mathrm{v})$. The seed culture of S. cerevisiae was incubated for $24-30 \mathrm{~h}$ and by the time the cell density was about $2.2-2.8 \mathrm{~g}$ dry cell weight $(\mathrm{DCW}) / \mathrm{l}$. Co-culture was begun by addition of the desired inoculum sizes of $S$. cerevisiae and desired amount of SF into the culture of $A$. cellulolyticus at different addition times. The SF as a powder was used for a cellulase-inducing substrate and was steam-sterilized before use.

\section{Culture conditions of one-pot bioethanol production in a shake flask}

To investigate medium components, culture temperature, agitation rate, and addition of $S$. cerevisiae inoculum for ethanol production in one-pot, co-culture was carried out in $500 \mathrm{ml}$ Erlenmeyer flask with $50 \mathrm{ml}$ medium. Medium is an important factor for producing both ethanol and cellulase with two different microorganisms. Preliminary test revealed yeast extract and polypeptone were the most effective nutrient at $\mathrm{pH} 4.5$ and $28^{\circ} \mathrm{C}$. Medium for A. cellulolyticus cultivation was added yeast extract, $0-7.5 \mathrm{~g} / \mathrm{l}$ and used for productions of cellulase and ethanol. The effect of the culture temperature on cellulase production by $A$. cellulolyticus was tested in the temperature range of $24-44^{\circ} \mathrm{C}$. To investigate the addition time of S. cerevisiae inoculum and SF for ethanol production, S. cerevisiae inoculum and SF were added at four different cellulase production phases, which was 48 , 60, 72, and 96 h. A. cellulolyticus and S. cerevisiae requires different oxygen level, in aerobic and anaerobic growth pattern, respectively. Cellulase production in the culture of A. cellulolyticus was carried out in 500-ml Erlenmeyer flasks in a rotary shaker at an agitation rate of $220 \mathrm{rpm}$, but ethanol production in co-culture with S. cerevisiae with SF was carried out at different agitation rates of $80-220 \mathrm{rpm}$. After the addition of S. cerevisiae inoculum and SF, ethanol concentration and cellulase activity were measured.

\section{One-pot bioethanol production in a jar fermentor}

Three liters jar fermentor (MDL-80, Marubishi, Tokyo Japan) with a $1.67 \mathrm{l}$ working volume was used. One hundred and fifty millilitres of seed culture of $A$. cellulolyticus were added to $1350 \mathrm{ml}$ of cellulase production medium supplemented with nutrients, and then cultured at agitation rate of $500 \mathrm{rpm}$ and aeration rate of $1.5 \mathrm{vol}-$ ume per volume per min (vvm). Co-culture was begun by adding a $10 \%(\mathrm{v} / \mathrm{v})$ inoculum of $S$. cerevisiae and desired amount of SF as a powder into the culture of A. cellulolyticus at the desired culture time. After the addition of S. cerevisiae inoculum and SF, agitation rates decreased to 200 revolution per min (rpm). After culture, DCW of A. cellulolyticus $\left(\mathrm{DCW}_{\mathrm{A}}\right)$ and S. cerevisiae $\left(\mathrm{DCW}_{\mathrm{S}}\right)$ was measured. The culture broth was centrifuged at $9447 \mathrm{~g}$, and the supernatant was stored in a $4^{\circ} \mathrm{C}$ refrigerator before the measurement of a cellulase activity and ethanol and protein concentrations.

For the practical ethanol production from SF, the ethanol yield based on the initial SF $\left(Y_{e / S F} \mathrm{~g}\right.$ ethanol/g SF) and an overall ethanol production rate $\left(V_{\mathrm{e}}, \mathrm{g} / \mathrm{l} / \mathrm{h}\right)$ are defined as follow:

$$
\begin{aligned}
& Y_{e / S F}=\Delta C_{e} / C_{S F} \\
& V_{\mathrm{e}}=\Delta C_{e} / t_{\text {one-pot }}
\end{aligned}
$$

where, $\Delta C_{e}$ and $C_{S F}$ denote concentrations of produced ethanol and initial SF, respectively, and $t_{\text {one-pot }}$ indicates culture time including cellulase production, saccharification, and fermentation.

\section{Analytical methods}

Due to the difficulty in separating the mycelia of A. cellulolyticus $\mathrm{C}-1$ from $S$. cerevisiae cells during the co-culture, total intracellular nucleic acid concentration (INA) was measured [27] and converted to total DCW $\left(\mathrm{DCW}_{\mathrm{t}}\right)$ as follows [19].

$$
\begin{aligned}
& I N A(\mathrm{~g} / \mathrm{l})=1.72 \times \text { absorbance at } 260 \mathrm{~nm} \\
& \mathrm{DCW}_{\mathrm{t}}(\mathrm{g} / \mathrm{l})=16.565 \times I N A .
\end{aligned}
$$

However, since the INA value contained $S$. cerevisiae and A. cellulolyticus cell masses, DCW of A. cellulolyticus $\left(\mathrm{DCW}_{\mathrm{A}}\right)$ was calculated as follows.

$$
\mathrm{DCW}_{\mathrm{A}}=\mathrm{DCW}_{\mathrm{t}}-\mathrm{DCW}_{\mathrm{S}}
$$

where, $\mathrm{DCW}_{\mathrm{S}}$ denotes $\mathrm{DCW}$ of $S$. cerevisiae.

During the co-culture, the number of S. cerevisiae was counted and converted to $\mathrm{DCW}_{\mathrm{S}}$. A culture broth of the co-culture was diluted, stained with $0.4 \%$ trypan blue and its number was counted with hemacytometer (Hirschmann Em Techcolor, Eberstadt, Germany). The $\mathrm{DCW}_{\mathrm{S}}$ was determined using a calibration curve between $\mathrm{DCW}_{\mathrm{S}}$ and $S$. cerevisiae cell number. The harvested cells in the culture without solid components were re-suspended in distilled water and centrifuged again to remove medium components. The precipitate was dried at $105^{\circ} \mathrm{C}$. Correlation of $\mathrm{DCW}_{\mathrm{S}}$ and the cell number was as follow, 


$$
\begin{aligned}
\mathrm{DCW}_{\mathrm{S}}(\mathrm{g} / \mathrm{l})= & 1 \times 10^{-8} \times \text { cell number }(\text { cells } / \mathrm{ml}) \\
& +0.3431
\end{aligned}
$$

Cellulase activity was measured using the standard IUPAC procedure with Whatman No. 1 filter paper, and the activity was expressed in filter paper unit (FPU). The FPU unit is based on the International Unit (IU) in which the absolute amount of glucose at a critical dilution is $2 \mathrm{mg}$ for $0.5 \mathrm{ml}$ critical enzyme concentration for $60 \mathrm{~min}$ [28].

Reducing sugar was measured by dinitrosalicylic acid (DNS) [29]. Residual glucose concentration was measured by a biochemistry analyzer (2700 SELECT, YSI Life Sci., Yellow Springs, OH, USA).

Ethanol concentration was measured using a Gas Chromatography (Shimadzu-2014, Shimadzu Co. Ltd., Tokyo, Japan) using a packed column (Gaskuropack5460/80, GC 2014Glass ID.3.2 $\phi \times 2.1 \mathrm{~m}$, GL Science Co. Ltd., Tokyo, Japan), with the following operational conditions: temperature of column and detector were 110 and $250^{\circ} \mathrm{C}$, respectively, nitrogen gas flow rate $60 \mathrm{ml} / \mathrm{min}$ and the injected sample volume $2 \mu \mathrm{l}$.

The total soluble protein concentration in crude and enzyme solutions was measured by the Lowry method [30]. Protein standard was prepared using bovine serum albumin.

\section{Statistical analysis}

Statistical analysis of experimental data was performed by a factorial ANOVA, using the least significant difference by the STATISTICA software package (Ver 5.5, Tulsa, OK, USA).

\section{Additional files}

Additional file 1: Figure S1. DCW of A. cellulolyticus (A), cellulase production (B), and S. cerevisiae cell number (C) in co-culture of A. cellulolyticus and $S$. cerevisiae. Various $S$. cerevisiae inoculums were added to $2.5 \mathrm{ml}$ of $A$. cellulolyticus preculture in $500 \mathrm{ml}$ Erlenmeyer flask with working volume of $50 \mathrm{ml}$, and were co-cultured at $28^{\circ} \mathrm{C}$ for $120 \mathrm{~h}$. Inoculum sizes of S. cerevisiae in A and B were $2.5 \%$ (closed circles), 5.0\% (open squares), 5.75\% (open triangles), and $10.0 \%$ (open circles). S. cerevisiae cell number in C was measured at $24 \mathrm{~h}$ (open bars) and $48 \mathrm{~h}$ (closed bars). Error bars denote standard deviation $(n=3)$. As determined by ANOVA analysis, the cellulase activities affected by $S$. cerevisiae inoculum sizes in B are $p<0.001$

Additional file 2: Figure S2. Effect of nutrients addition on $\mathrm{DCW}_{\mathrm{A}}$ (A), cellulase activity (B), and ethanol production (C) in co-culture of A. cellulolyticus and S. cerevisiae. Ethanol production was carried out with addition of $50 \mathrm{~g} \mathrm{SF/I}$ and $10 \%$ inoculum at the culture time of $60 \mathrm{~h}$ with agitation rate of $220 \mathrm{rpm}$. Used medium was cellulase producingmedium containing various ratios of yeast extract and polypeptone, without its addition (closed squared); 5 and $10 \mathrm{~g} / \mathrm{l}$ (closed triangles); 2.5 and $5 \mathrm{~g} / \mathrm{l}$ (open circles); 5 and $0 \mathrm{~g} / \mathrm{l}$ (open squares); 0 and $10 \mathrm{~g} / \mathrm{l}$ (open triangles). Arrows indicate inoculum and SF-addition time. Error bars denote standard deviation $(n=3)$. As determined by ANOVA analysis, the cellulase activities (B) and ethanol concentrations (C) affected by yeast extract are $p$ value of 0.0004 and 0.0027 , respectively.

Additional file 3: Figure S3. Effect of yeast extract on $\mathrm{DCW}_{\mathrm{A}}(\mathrm{A})$, cellulase activity (B), and $\mathrm{DCW}_{\mathrm{S}}(\mathrm{C})$, ethanol production (D) in coculture of $A$. cellulolyticus and $S$. cerevisiae. Ethanol production was carried out with addition of $50 \mathrm{~g} \mathrm{SF/I}$ and $10 \%$ inoculum at the culture time of $60 \mathrm{~h}$ with agitation rate of $220 \mathrm{rpm}$. Used medium was cellulase producing-medium containing various concentrations of yeast extract, without addition (closed circles); $2.5 \mathrm{~g} / \mathrm{l}$ (closed squares); $5 \mathrm{~g} / \mathrm{l}$, (closed triangles); $7.5 \mathrm{~g} / \mathrm{l}$ (open circles). Arrows indicate inoculum and SF-addition time. Error bars denote standard deviation $(n=3)$. As determined by ANOVA analysis, the cellulase activities and ethanol concentrations affected by yeast extract concentration in $\mathrm{B}$ and $\mathrm{D}$ are both significant at $p<0.0001$, respectively.

\section{Abbreviations}

ANOVA: analysis of variance; CBP: consolidated bioprocess; DCW: dry cell weight; $D_{C W}$ : dry cell weight of $A$. cellulolyticus; $D_{C W}$ : dry cell weight of S. cerevisiae; DCW: dry cell weight of A. cellulolyticus and S. cerevisiae; PS: paper sludge; SF: Solka-Floc; SSF: simultaneous saccharification and fermentation: $V_{\mathrm{e}}$ overall ethanol production rate in one-pot bioethanol production process $(\mathrm{g} / \mathrm{l} / \mathrm{h}): Y_{\text {e/SF, }}$ the ethanol yield based on the initial SF (g ethanol/g SF).

\section{Competing interests}

The authors declare that they have no competing interests.

\section{Authors' contributions}

EYP directly supervised the project, participated in its experimental design, data interpretation, and was responsible for writing the manuscript. KN carried out the co-culture, the hydrolysis and fermentation experiments. TK participated in handling and discussion of co-culture of A. cellulolyticus and S. cerevisiae cells. All authors have read and approved the manuscript.

\section{Acknowledgements}

We thank to Dr. Naoyuki Okuda of Tsukishima Kikai Co. Ltd. (Tokyo, Japan) for kindly providing A. cellulolyticus C-1 strain for this study.

Received: 4 June 2012 Accepted: 30 August 2012

Published: 31 August 2012

\section{References}

1. Thurnheer T, Cook AM, Leisinger T: Co-culture of defined bacteria to degrade seven sulfonated aromatic compounds: efficiency, rates and phenotypic variations. Appl Microbiol Biotechnol 1988, 29:605-609.

2. Shim H, Shin EB, Yang ST: A continuous fibrous-bed bioreactor for BTEX biodegradation by a co-culture of Pseudomonas putida and Pseudomonas fluorescens. Adv Environ Res 2002, 7:203-216.

3. Parshina SN, Kijlstra S, Henstra AM, Sipma J, Plugge CM, Stams AJM: Carbon monoxide conversion by thermophilic sulphate-reducing bacteria in pure culture and in co-culture with Carboxydothermus hydrogenoformans. Appl Microbiol Biotechnol 2005, 68:390-396.

4. Laplace JM, Delgenes JP, Moletta R, Navarro JM: Ethanol production from glucose and xylose by separated and co-culture processes using high cell density systems. Proc Biochem 1993, 28:519-525.

5. Taniguchi M, Tohma T, Itaya T, Fujii M: Ethanol production from a mixture of glucose and xylose by co-culture of Pichia stipites and a respiratorydeficient mutant of Saccharomyces cerevisiae. J Ferment Bioeng 1997, 83:364-370.

6. Qian M, Tian S, Li X, Zhang J, Pan Y, Yang X: Ethanol production from diluted-acid softwood hydrolysate by co-culture. Appl Biochem Biotechnol 2006, 134:273-283.

7. Golian H, Dumsday GJ, Stanley GA, Pamment NB: Evaluation of a recombinant Klebsiella oxytoca strain for ethanol production from cellulose by simultaneous saccharification and fermentation: comparison with native cellobiose-utilising yeast strains and performance in co-culture with thermotolerant yeast and Zymomonas mobilis. J Biotechnol 2002, 96:155-168. 
8. Saddler JN, Chan MKH, Lous-Seize G: A one-step process for the conversion of cellulose to ethanol using anaerobic microorganisms in mono-and co-culture. Biotechnol Lett 1981, 3:321-326.

9. Lynd LR, Weimer PJ, van ZyI WH, Pretorious IS: Microbial cellulose utilization: fundamentals and biotechnology. Microbiol Mol Biol Rev 2002, 66:506-577.

10. Lynd LR, van Zyl WH, McBride JE, Laser M: Consolidated bioprocessing of cellulosic biomass: an update. Curr Opin Biotechnol 2005, 16:577-583.

11. Aro N, Pakula T, Penttila M: Transcriptional regulation of plant cell wall degradation by filamentous fungi. FEMS Microbiol Rev 2005, 29:719-739.

12. Gold ND, Martin VJJ: Global view of the Clostridium thermocellum cellulosome revealed by quantitate proteomic analysis. J Bacteriol 2007. 189:6787-6795.

13. $X u$ Q, Singh A, Himmel ME: Perspectives and new directions for the production of bioethanol using consolidated bioprocessing of lignocellulose. Curr Opin Biotechnol 2009, 20:364-371.

14. Fujita $Y$, Ito J, Ueda M, Fukuda $H$, Kondo A: Synergistic saccharification, and direct fermentation to ethanol, of amorphous cellulose by use of an engineered yeast strain codisplaying three types of cellulolytic enzyme. Appl Environ Microbiol 2004, 70:1207-1212.

15. Katahira S, Mizuike A, Fukuda $H$, Kondo A: Ethanol fermentation from lignocellulosic by a recombinant xylose- and cellooligosaccharideassimilating hydrolysate yeast strain. Appl Microbiol Biotechnol 2006, 72:1136-1143

16. Khaw TS, Katakura Y, Koh J, Kondo A, Ueda M, Shioya S: Evaluation of performance of different surface-engineered yeast strains for direct ethanol production from raw starch. Appl Microbiol Biotechnol 2006 , 70:573-579

17. Yanase S, Yamada R, Kaneko S, Noda H, Hasunuma T, Tanaka T, Ogino C, Fukuda $\mathrm{H}$, Kondo A: Ethanol production from cellulosic materials using cellulase expressing yeast. Biotechnol J 2010, 5:449-455.

18. Yamanobe T, Mitsuishi Y, Takasaki Y: Isolation of cellulolytic enzyme producing microorganism, culture conditions and some properties of the enzymes. Agric Biol Chem 1987, 51:65-74

19. Ikeda Y, Hayashi H, Okuda N, Park EY: Efficient cellulase production by the filamentous fungus Acremonium cellulolyticus. Biotechnol Progr 2007, 23:333-338.

20. Park EY, Naruse K, Kato T: Improvement of cellulase production in cultures of Acremonium cellulolyticus using pretreated waste milk pack with cellulase targeting for biorefinery. Bioresour Technol 2011, 102:6120-6127.

21. Prasetyo J, Zhu J, Kato T, Park EY: Efficient production of cellulase in the culture of Acremonium cellulolyticus using untreated waste paper sludge. Biotechnol Progr 2011, 1:104-110.

22. Park EY, Anh PN, Okuda N: Bioconversion of waste office paper to $L$ (+)-lactic acid by filamentous microorganism Rhizopus oryzae. Bioresour Technol 2004, 93:77-83.

23. Ikeda Y, Park EY, Okuda N: Bioconversion of waste office paper to gluconic acid in a turbine blade reactor by the filamentous fungus Aspergillus niger. Bioresour Technol 2006, 97:1030-1035.

24. Prasetyo J, Naruse K, Kato T, Boonchird C, Harashima S, Park EY: Bioconversion of paper sludge to biofuel by simultaneous saccharification and fermentation using a cellulase of paper sludge origin and thermotolerant Saccharomyces cerevisiae TJ14. Biotechno Biofuel 2011, 4:35.

25. Prasetyo J, Sumita S, Okuta N, Park EY: Response of cellulase activity in $\mathrm{pH}$-controlled cultures of filamentous fungus Acremonium cellulolyticus. Appl Biochem Biotechnol 2010, 162:52-61.

26. Kansarn S: A novel concept for the enzymatic degradation mechanism of native cellulose by Acremonium cellulolyticus. Sch Electr Sci Res Rep 2002, 23:89-91. Shizuoka University Repository (SURE), 91. http://hdl.handle.net/ 10297/1453

27. Schneider WC: Phosphorous compounds in animal tissues. 1. Extraction and estimation of deoxypentose nucleic acid. J Biol Chem 1945, 161:293-295.
28. Ghose TK: Measurement of cellulase activities. International union of pure and applied chemistry. Pure App/ Chem 1987, 59:257-268.

29. Summer JB, Howell SF: A method for determination of saccharase activity. J Biol Chem 1935, 108:51-54.

30. Lowry OH, Rosebrough NJ, Farr AL, Randall RJ: Protein measurement with the folin-phenol reagent. J Biol Chem 1951, 193:265-275.

doi:10.1186/1754-6834-5-64

Cite this article as: Park et al:: One-pot bioethanol production from cellulose by co-culture of Acremonium cellulolyticus and Saccharomyces cerevisiae. Biotechnology for Biofuels 2012 5:64

\section{Submit your next manuscript to BioMed Central and take full advantage of:}

- Convenient online submission

- Thorough peer review

- No space constraints or color figure charges

- Immediate publication on acceptance

- Inclusion in PubMed, CAS, Scopus and Google Scholar

- Research which is freely available for redistribution

Submit your manuscript at www.biomedcentral.com/submit
C Biomed Central 